
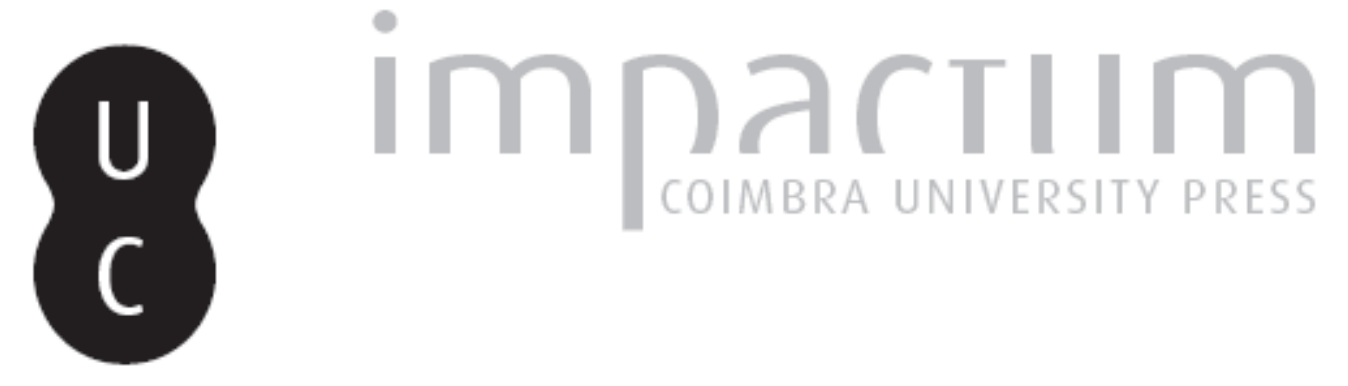

\title{
Regeneração e degeneração: o contínuo Futurismo
}

\author{
Autor(es): $\quad$ Sargento, Pedro
}

Publicado por: Imprensa da Universidade de Coimbra

URL persistente:

URI:http://hdl.handle.net/10316.2/42572

DOI:

DOl:https://doi.org/10.14195/0870-8584_4_3

Accessed : $\quad$ 26-Apr-2023 10:56:59

A navegação consulta e descarregamento dos títulos inseridos nas Bibliotecas Digitais UC Digitalis, UC Pombalina e UC Impactum, pressupõem a aceitação plena e sem reservas dos Termos e Condições de Uso destas Bibliotecas Digitais, disponíveis em https://digitalis.uc.pt/pt-pt/termos.

Conforme exposto nos referidos Termos e Condições de Uso, o descarregamento de títulos de acesso restrito requer uma licença válida de autorização devendo o utilizador aceder ao(s) documento(s) a partir de um endereço de IP da instituição detentora da supramencionada licença.

Ao utilizador é apenas permitido o descarregamento para uso pessoal, pelo que o emprego do(s) título(s) descarregado(s) para outro fim, designadamente comercial, carece de autorização do respetivo autor ou editor da obra.

Na medida em que todas as obras da UC Digitalis se encontram protegidas pelo Código do Direito de Autor e Direitos Conexos e demais legislação aplicável, toda a cópia, parcial ou total, deste documento, nos casos em que é legalmente admitida, deverá conter ou fazer-se acompanhar por este aviso.

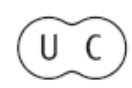




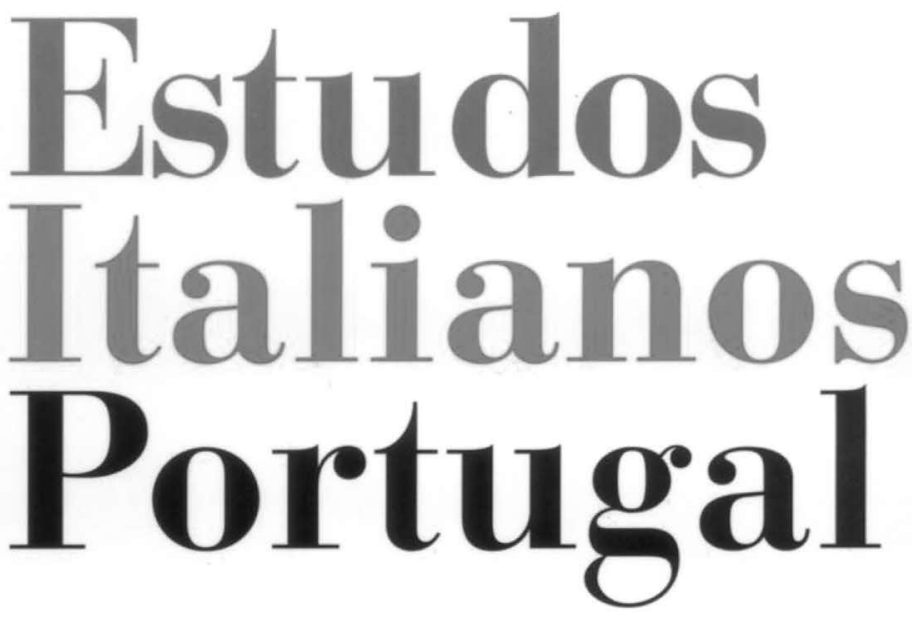

Instituto

Italiano

de Cultura

de Lisboa

Nova Série

$\mathbf{N}^{\mathbf{0}} 4$.

2009 


\title{
REGENERAÇÃO E DEGENERAÇÃO: O CONTÍNÜO FUTURISMO
}

\author{
Pedro Sargento*
}

\section{Futurismo e Lifestyle}

QuANDo o Futurismo se apresentou formalmente com a publicação do primeiro manifesto em 1909, já a Europa fervilhava de movimentos descritíveis como "alternativos". Grupos e correntes como Die Brücke, os Secessionistas vienenses, os Fauves, ou as primeiras expressões do Cubismo assinalavam, com a sua simples presença, um incómodo artístico que atingiu o meio intelectual europeu de forma simultânea e alargada, iniciando o período das vanguardas artísticas. $\mathrm{Na}$ sua base, uma vontade de romper com os princípios que regiam a arte académica, que desde há muito se dedicava a uma estagnada e circular procura pelo belo na Natureza e pelo valor simbólico e iconográfico da mitologia, como tal seguindo - é justo dizer, sem grande inventividade - a regra da imitação e do realismo das formas. Os grupos alternativos

* Pedro Sargento é licenciado em Filosofia pela Universidade de Lisboa. Estudou em Viena e Turim, onde foi bolseiro da Fundação Calouste Gulbenkian no "Instituto de Estudos Filosófico-Religiosos Luigi Pareyson", concentrando-se nos principais temas da ontologia da liberdade desenvolvida por este filósofo. Actualmente, é membro do projecto "Filosofia e Paisagem: a visão estética do mundo natural" da Universidade de Lisboa e aluno de doutoramento na Universidade de Roma "Tor Vergata", onde conduz uma investigação sobre o conceito de forma na estética contemporânea. 
tinham em comum a vontade em encontrar novos territórios para as artes figurativas, desafiando o campo da arte do ponto de vista teórico e institucional.

Também a estética se encontrava numa espécie de momento de apreensão. Nascida no século XVIII pela necessidade de envolver numa só disciplina todas as questões que envolvem a sensibilidade, a estética vivia então ainda na ressaca da sua redução a uma filosofia da arte, por parte de Hegel. E mesmo esta estava destinada a perder o seu significado porque superada, no momento em que a afirmação plena do Espírito a tornasse obsoleta. Se quisermos delinear os maiores contributos dos movimentos artísticos de entre o final do século XIX e os primeiros anos do século XX para as artes figurativas, é obrigatório realçar a capacidade de invenção de novas linguagens, animada por um despudorado experimentalismo. Mas, mais do que uma inovação nos aspectos formais, estes também procederam a uma reabilitação da arte enquanto categoria da reflexão estética, investindo-a de uma grande variedade de "futuros possíveis" a partir da quebra da sua relação de dependência com a beleza antiga, identificando-a com o que é novo e actual. $O$ facto de os seus esforços se terem concentrado quase exclusivamente no âmbito artístico impede-nos porém de conferir às primeiras vanguardas a consumação de uma revolução estética total, pois a sua acção deixou de fora outros campos da sensibilidade. Por outro lado, a parcialidade desta convulsão estética produziu um estímulo, reforçado pelo aparecimento do programa futurista, ampliando as suas consequências não só para a disciplina, mas para o sentir enquanto relação fisiológica com o mundo.

Um dos motes mais importantes para as vanguardas é o famoso "il faut être absolument moderne" de Rimbaud. No caso do Futurismo, a necessidade de modernidade foi mais além do que o imperativo da novidade em arte. O Futurismo caracteriza-se por apresentar um verdadeiro programa 
de refundação transversal a todos os aspectos sociais, da política à arquitectura, de todas as formas de arte à culinária e à publicidade. Foi Marinetti o grande agitador do movimento futurista mas também do novo século italiano, mostrando-se como o emissário de uma forma de estar que fazia justiça à aceleração constante da vida em todos os seus aspectos. Esta atitude esbarrava frontalmente com uma vigente monotonia pós-ressurgimental, nostálgica e acomodada. No entretanto, uma nova geração surgira sob o signo revolucionário e cosmopolita.

A postura do Futurismo foi desde o início demonstrar que as profundas transformações na ordem do mundo e na vida social que a Revolução Industrial trouxe foram assimiladas de modo errado (ou não o foram de todo) pela classe intelectual italiana. Para se impor como força renovadora o movimento teve de lutar contra o êxito perverso dessas transformações: o de esbarrarem na indiferença do espírito comodista burguês, imbuído de um ideal romântico e simbolista trazido do século anterior sem qualquer transposição modernista na esfera cultural.

Marinetti, que além de literato pode sem dúvida ser visto como o precursor da figura do relações públicas, intuiu aquela regra fundamental do marketing que prescreve maior importância ao facto de um determinado produto ser falado antes de ser apreciado, isto é, que é imprescindível ser-se conhecido antes de se ser reconhecido. De resto, a Itália conservadora tinha também encontrado o seu Vate, o poeta vidente que exprimia na perfeição o sentimento das massas, em Gabriele D’Annunzio, também ele tão hábil na autopromoção e na personificação de um ideal quanto Marinetti. O programa futurista assentava na ideia de que o progresso técnico-científico tinha de se fazer acompanhar por uma renovação intelectual, institucional e artística, que se deveria manifestar desde logo na sensibilidade individual e nas acções dos seus promotores. O primeiro ponto do manifesto 
inaugural é elucidativo: "Nós queremos cantar o amor ao perigo, a disposição à energia e à temeridade".

Esta necessidade de alargar a visão do mundo futurista a todas as áreas da cultura implicou a adopção de um programa político. A luta ideológica futurista não poderia, todavia, exteriorizar-se numa actividade de debate de ideias e de conceitos, precisamente porque o que era urgente era "abrir os olhos" da sociedade para o que já se tinha efectivado como real. Não havia disputa possível. Enaltecer a guerra como única higiene do mundo, como se lê também no primeiro manifesto, mostra a imperativa vontade em adoptar uma atitude radical e em incarnar um espírito pioneiro, iconoclasta e guerreiro, qualidades pouco compatíveis com o diálogo, seja com os erráticos contemporâneos, seja mesmo com a História e com todas as suas conquistas, e é esta a razão pela qual a retórica futurista incide quase completamente na ideia de que é necessário destruir o passado. Sob este aspecto, é interessante notar que a ideia de política que o Futurismo adopta encontra eco nas ideias de Max Weber, que naquele mesmo período desenvolvia uma teoria política baseada nas ideias de decisão emocional, de luta e de Beruf, palavra alemã que, para além de se traduzir como "profissão", tem também o significado de "vocação" e, ainda mais expressivamente, de um daimónico "chamamento".

Para além das vicissitudes políticas do movimento e principalmente do seu pai fundador, a capacidade do Futurismo para se mostrar "absolutamente moderno" reside sobretudo, do nosso ponto de vista, na forma como este activismo se apropriou de uma dimensão estética que sempre interessou os filósofos e que comparece na própria fundação histórica da disciplina: trata-se do modo de viver, do estilo de vida exemplar e do modo de aparecer e de se apresentar. A temática dos estilos de vida aparece como categoria estética originária na medida em que ela deriva da integração das ques- 
tões ligadas à educação nesse novo corpo de saberes que o século XVIII criou. A importância dada aos comportamentos e à condução de uma "vida exemplar", enaltecida por Schiller, é contemporânea à individuação do belo e da arte como as restantes dimensões capazes de produzir uma experiência particular no sujeito. A esta especificidade do enlevo estético corresponde a necessidade de um refinamento pessoal que, para os românticos, seria o fundamento de uma conciliação universal através da estética. Por seu lado, o Futurismo, mas em particular Marinetti, apercebeu-se da funcionalidade comunicativa do lifestyle e de uma expressividade insubstituível que se refere somente à forma como o puro "exterior" da acção, sugerindo que a dimensão ritual e iterativa tem maior força e é mais consequente do que o próprio conteúdo que quer veicular ${ }^{1}$. O lifestyle não chega a anular o valor conceptual interior à acção mas aplica-se numa maximização do poder da imagem, por forma a tornar verosímil e convincente o rosto sensível da ideia, como estratégia de persuasão e de aceitação.

Para um projecto empenhado em acordar a sensibilidade da época para a nova realidade ágil, dinâmica, ruidosa e violenta, a entrada em cena teria de se dar sob o signo do chocante. O comportamento e a retórica dos seus protagonistas mostra uma consciência plena da eficácia processual que tem um estilo de vida difundido como exemplar, agindo como se fossem os profetas de um novo mundo ${ }^{2}$, como se respon-

1 Para um aprofundamento desta temática: Mario Perniola, Transiti. Filosofia e Perversione, Castelvecchi, Roma 1998.

2 Veja-se a este propósito, para além da noção de "habitus" tratada em boa parte da obra de Pierre Bourdieu, o já clássico texto de Norbert Elias, Über den Prozeß der Zivilisation, Haus zum Falken, Basileia 1939 (O Processo Civilizacional, trad. port. Lídia Campos Rodrigues, Dom Quixote, 1989-1990) para uma evolução histórica do comportamento como factor de identidade e distinção entre classes e o importante estudo de Renato Poggioli, Teoria dell'arte d'avanguardia, Il Mulino, Bolonha 1962, para uma análise centrada na postura pública das vanguardas. 
dessem a um chamamento. Os ajuntamentos futuristas com finalidade persecutória, os célebres serões nos teatros, onde se proclamava a "volúpia de ser assobiado" e onde muitas vezes tudo acabava em pancadaria, a arquitectura efémera de Sant'Elia, as "palavras em liberdade" de Marinetti (onde a forma do poema suprime quase completamente o conteúdo), os concertos executados com o intonarumori dos compositores Luigi Russolo e Balilla-Pratella ou a roupa futurista de Giacomo Balla, tudo no Futurismo evoluía tendo em vista a imposição de uma nova sensibilidade, tendendo a uma revolução estética total a partir da forma e do habitus, reconduzindo a acção do movimento à formação histórica da disciplina através de uma reapropriação original.

\section{BoCCIONI E A POÉticA FUTURISTA FIgURAdA: DINAMISMO, SIMULTANEIDADE, COMPENETRAÇÃO}

$\mathrm{Na}$ globalidade da análise histórica, a poética futurista, entendida como os fundamentos teóricos da sua execução artística, tende a permanecer na sombra da expansividade mundana do movimento e na importância cultural do seu pioneirismo. No entanto, também esta é atravessada interiormente pelo mesmo jogo de forças divergentes do programa futurista, suspenso entre renovação e reabilitação, demolição e persistência.

Em 1914 o escritor, pintor e escultor Umberto Boccioni publicava Pittura Scultura Futuriste ${ }^{3}$, que vale como o texto mais estruturado e mais sistemático de todo o Futurismo, articulando crítica histórica e teoria das artes figurativas.

Uma vez que o Futurismo se posiciona no domínio público como movimento anti-passadista e anti-tradicionalista, pode parecer surpreendente que os fundamentos teó-

\footnotetext{
${ }^{3}$ Umberto Boccioni, Pittura Scultura Futuriste, Edizioni Futuriste di Poesia, 1914.
} 
ricos com os quais Boccioni anunciava a superioridade da arte futurista convirjam no conceito de continuidade. A continuidade constitui o elemento central que articula os elementos compositivos que o Futurismo idealizou para a arte. Estes "primitivos de uma nova sensibilidade completamente transformada", como todas as outras vanguardas artísticas entre os dois séculos, vêem a arte como o reflexo do que de mais profundo marca a realidade do seu tempo e ao mesmo tempo como um veículo essencial para promover e instalar uma percepção generalizada dessa realidade, destruindo aquela que a precede. No caso dos futuristas, desde os primeiros manifestos "generalistas" que os eixos de uma nova sensibilidade são a dinâmica e a simultaneidade, complementando-se, nos manifestos técnicos, com a noção de compenetração dos planos. Ao observar as primeiras pinturas plenamente aderentes ao Futurismo, como as de Boccioni, Balla ou Carrà entre 1909 e 1912-13, verificamos a urgência de complementar a representação de dinâmica, que é movimento e velocidade, com aquela de simultaneidade ininterrupta de fenómenos. Delinear tais elementos no quadro implica tornar sensível a permanente modificação do estado de coisas que caracteriza a realidade emergente, seja na proliferação de estaleiros, na abundância de novos objectos ou na súbita proximidade entre lugares oferecida pelo automóvel, pelo comboio e pelo avião. Conta principalmente exaltar os objectos no seu permanente devir. Se a arte mimética desprezada pelo Futurismo promovia na sua maior parte o ideal de uma estética-estática que tem como finalidade a observação da beleza das formas, o novo programa é aquele de conseguir a representação da mudança, não só de um objecto em particular, mas de todo o complexo formado pela interacção dos objectos com o seu ambiente. A dinâmica, para ser representativa, deve ser generalizada, e o mesmo é válido para a simultaneidade, que significa precisamente presença generalizada do movimento. 
Apenas a continuidade consegue conjugar a necessidade de representar uma contínua transformação dos estados de coisas na imobilidade fisica de um quadro. O grande programa técnico da pintura futurista foi tornar actual um presente trespassado de passado e de futuro, conjugando todas as dimensões temporais. Assim, a obra de arte procura a unidade que sintetiza a mudança e a variedade através da continuidade que deve sobressair no espaço figurativo. Trata-se de "procurar a forma única que dê a continuidade no espaço"4.

$\mathrm{Na}$ base da germinação destas ideias está o acolhimento que os futuristas deram ao pensamento de Henri Bergson ${ }^{5}$. Boccioni, mais do que todos os outros, procede a uma verdadeira transposição dos conceitos bergsonianos de duração e intuição para o campo da teoria da arte. Segundo Bergson, a duração é a forma como a consciência procede a uma distinção entre o espaço e o tempo, preenchendo-se com os objectos da nossa percepção a partir da sua sucessão meramente temporal, na qual é impossível a sobreposição de dois objectos (ou de dois "dados da consciência") e, como tal, a realidade é percebida como um contínuo e irrefreável devir, uma sucessão onde cada elemento é imediatamente substituído por outro. Por sua vez, a intuição permite-nos identificar os objectos, tal como nos aparecem em sucessão contínua à consciência, com o seu fundamento exterior, pois esta é a capacidade de nos transportarmos para fora da cons-

${ }^{4}$ Boccioni, op. cit., p. 196. A escultura mais representativa de Boccioni tem como título Formas únicas da continuidade no espaço (1913) e está conservada na galeria Tate Modern de Londres.

5 Quando o movimento futurista irrompeu Bergson havia já publicado Essai sur les donées immediates de la conscience (1889) (Ensaio sobre os dados imediatos da consciência, trad. port. João da Silva Gama, Edições 70, Lisboa 1988), Matiére et memoire (1896), Le rire (1900) (O Riso. Ensaio sobre a significação do cómico., trad. port. Miguel Serras Pereira, Relógio D’Àgua, Lisboa 1991) La pensée et le mouvant (1903) e L'evolution créatrice (1907) (trad. port. Pedro Elói Duarte, Edições 70, Lisboa 2001). 
ciência subjectiva e identificarmo-nos com o "mundo das coisas". Por outras palavras, a duração é a sensação que se tem de um objecto e a intuição é o conhecimento do objecto. Assim, o limite interposto entre o sujeito e o objecto artístico, adoptado pelo academismo artístico italiano do século XIX dominado pelos paradigmas da imitação e da apreciação, acabam por ser destituídos e superados, pois esta nova relação determina a convivência entre o sujeito (criador ou espectador da obra) e o objecto. A partir deste reordenamento das bases da experiência artística, Boccioni proclama o famoso mote "nós colocaremos o espectador no centro do quadro", que aparece no Manifesto Técnico da Pintura Futurista de 1910. A duração e a intuição servem como princípios renovadores em relação aos lugares clássicos do sujeito e da obra, pois constroem uma poética fundada na continuidade entre sensação e compreensão. A duração dá-nos a forma de um real dinâmico, simultâneo e violento, enquanto a intuição nos transporta para o centro da realidade, através de um processo emulativo que dispõe cada sujeito no interior do mundo tal qual este se lhe assoma à consciência, tornando-se assim actor e espectador de uma experiência estética total.

A relação entre o quadro e o espectador encontra uma expressão análoga, no interior da técnica pictórica futurista, na ideia da compenetração dos planos. Segundo Boccioni, o que distingue a arte futurista do Cubismo é a possibilidade de desconstruir o objecto, nas suas várias dinâmicas, a partir do interior do próprio objecto e do espaço que o circunda, e não apenas como um mero desmultiplicar das suas perspectivas possíveis. Para Boccioni, o Cubismo tem o mérito de apresentar em pintura o objecto "desenvolto, desunido, esfacelado, multiplicado" mas com esta "decomposição" limita-se a oferecer uma espécie de ponto de vista absoluto 
sobre o objecto, mantendo o quadro e o sujeito em reinos separados, e como tal negando a intuição que permite a continuidade entre a sensação e o conhecimento. Se só esta continuidade permite a emotividade violenta com a qual a arte futurista pretende reflectir o progresso humano baseado no avanço tecnológico, é essencial que no interior da obra tudo se ligue a tudo, ou seja, que os elementos singulares representados se construam em interacção com o espaço que os circunda, e vice-versa.

O diálogo com as correntes artísticas que antecederam ou que concorrem com o Futurismo ${ }^{7}$ inclui também uma análise dos princípios pictóricos do Impressionismo. Embora o tom se mantenha prevalentemente crítico, na verdade Boccioni reconhece amplamente a importância dos resultados deste estilo, tanto do ponto de vista histórico como técnico. Segundo o pintor, foi o Impressionismo o primeiro movimento a dar uma real importância ao espaço, aparentemente vazio, que está entre os diversos elementos de uma pintura. No entanto, impressionistas como Monet ou Renoir concentraram-se numa procura pela função luminosa do ambiente exterior, dedicando por isso mesmo toda a atenção à cor e aos ritmos cromáticos, pois são estes que em primeiro lugar afectam a sensibilidade, libertando a impressão instantânea que dá nome ao movimento. Assim considerado, o Impressionismo refugia-se demasiadamente numa procura

7 O confronto da arte futurista com o seu próprio tempo desdobra-se numa multiplicidade de questões relacionadas com a questão do estatuto da obra de arte e da arte enquanto fenómeno expressivo. Por um lado a ideia de que a arte pode e deve ter como fim último apenas a sua própria afirmação e presença, que tem uma utilidade intrínseca e que qualquer justificação que lhe seja exterior apenas a desvirtua. Este é o princípio da "arte pela arte" que afunda as suas raízes no Estetismo, ligado ao Decadentismo que percorre a segunda metade do século XIX e que encontra o seu apogeu (ou talvez a sua expressão degenerada) no Dadaísmo. Do outro lado encontramos a arte como expressão de uma realidade ainda não totalmente desvelada e percebida, e portanto a ideia de que a arte tem como finalidade referir-se à vida, como no caso do Futurismo. 
analítica pelas potencialidades da cor e pela sua capacidade de enaltecer a sensação que se quer representar no quadro, da mesma forma que o Cubismo se concentra numa investigação de cunho conceptual de decomposição dos objectos na pluralidade das suas perspectivas, abordando a criação a partir da cosa mentale, isto é, da ideia, da forma e do intelecto. Boccioni afirma que o objectivo da arte futurista é o de tomar os princípios aflorados na pintura impressionista e levá-los ao extremo, ou seja, pegar na concepção de espaço como o meio pelo qual as figuras estão relacionadas (através da "vitalização da luz") e "solidificá-lo", transformando o ar, ou a típica neblina impressionista, num verdadeiro corpo condutor que torna a totalidade dos elementos compositivos em corpos actuantes e interactivos, de modo a fazer do quadro o palco de uma intrépida agitação dinâmica de formas e linhas-força. Com efeito, Boccioni afirma que a representação do instante impressionista deve dar lugar à representação do acidente futurista ${ }^{8}$.

A poética futurista anuncia uma síntese do Impressionismo que na verdade é uma síntese da relação de oposição entre o Impressionismo e o Cubismo, e portanto uma síntese entre o primado da sensação e o primado do intelecto. O confronto com os movimentos artísticos reproduz assim a interpretação estética da filosofia de Bergson, e, mais importante, parece muito mais empenhada em proceder a uma actualização dos fenómenos precedentes do que propriamente em destruí-los. Também aqui é o conceito de continuidade que continua a regular o tratamento estético que o Futurismo concedeu aos fenómenos dos quais se pretende diferenciar, prestando assim um inesperado culto ao passado que deve ser evidenciado?.

${ }^{8}$ Boccioni, op. cit., p. 103.

9 Na recente obra Les origines mythiques du Futurisme (PU Paris-Sorbonne, Paris, 2009), Mariana Cescutti analisa as origens da obra de Marinetti à luz da sua relação com os mestres do Simbolismo (Baudelaire, Mallarmé, Verlaine) 


\section{A DEgENERAÇÃo DO PROGRAMA FUtURISTA}

A campanha futurista parece assim fundar-se sobre uma rentabilização de uma categoria estética clássica algo ignorada do ponto de vista teórico, mas que se mostra em permanência nas diversas épocas, e numa actualização sintética de elementos artísticos e filosóficos do seu passado imediato. O movimento que se edificou a partir de uma agressiva denúncia do passado contribuiu para a sua reconversão integrando-lhe os elementos dominantes do seu tempo. A sua estratégia ideológica pode assim ser descrita como uma hermenêutica realista velada, capaz de mudar radicalmente o espectro cultural simplesmente continuando alguns dos aspectos filosófico-artísticos anteriores, vestindo o passado de modernidade. Este aspecto continuativo do Futurismo pode contribuir para mostrar como o presente é uma reconversão permanente do passado, levando-nos a paradoxal tese de que o passado vive continuamente e que cada elemento do presente é a reabilitação, a reconversão do seu próprio passado. Seria então possível falar da história da arte e da história da cultura como uma persistente cadeia de metamorfoses da qual está excluída a absoluta originalidade, e que, como defende George Kubler em A Forma do Tempo, cada desenvolvimento, mesmo no mais modesto utensílio, não é mais do que o repropor de uma resposta a um problema que existiu, virtualmente, desde sempre? ${ }^{10}$

Partindo desta consideração, podemos começar a traçar uma teoria da cultura que gira em torno do eixo regeneração/degeneração. A regeneração visa o diálogo de um

contra os quais o movimento se pronuncia explicitamente. A obra pretende estabelecer, ao invés, a continuidade entre ambos mostrando como o Futurismo foi reescrevendo o legado do Simbolismo e, através de uma sucessão de metamorfoses estilísticas, adquirindo a sua identidade.

${ }^{10}$ George Kubler, The Shape of Time, New Haven University Press, 1972 (A Forma do Tempo, trad. port José Vieira de Lima, Vega, Lisboa, 1998). 
movimento cultural com o seu "passado homólogo", e a degeneração considera a mutação desses elementos (conceitos, ideologias, estilos) através do próprio tratamento criativo que os movimentos lhes conferem. O Futurismo apresenta-se neste contexto como um fenómeno exemplar, porque a sua regeneração e síntese de elementos do passado é produzida contemporaneamente ao anúncio da intenção de os erradicar. Quando Marinetti afirma que o automóvel rugidor é mais belo do que a Vitória de Samotrácia, ele parece entrever toda a "sequência formal", para usar a expressão de Kubler, que transporta ao longo da história a representação do movimento e da dinâmica, da qual esta escultura é um dos maiores exemplos da antiguidade, até à sua expressão actual: o automóvel, representante moderno destes atributos, elevado, ainda por cima, a ícone de beleza, a peça de design e a status symbol, sendo de todo em todo significativo que a estátua atribuída a Pitócrito de Rodes tenha sido adoptada como o símbolo da Rolls Royce. O movimento futurista apresenta-se-nos como uma unidade orgânica de processamento do passado através de uma continuidade que actualiza. É um laboratório de reapropriação que através da repetição cria o presente e coloca o futuro em movimento. $\mathrm{Na}$ repetição, criadora de "jogo de diferenças" (usando a expressão de Deleuze), o Futurismo desvela toda a força do seu próprio nome.

Mas então o que é feito, cem anos depois, dos elementos estruturais do Futurismo? Ou melhor, de que modo nos é possível interpretar hoje este movimento? Existem duas direcções conflituais, ambas com importantes implicações para a Estética. A primeira obstina-se a ver no Futurismo uma "coisa do passado", nos termos em que é representada por uma tendência surgida nos anos oitenta designada por paleofuturismo ou retrofuturismo. Trata-se, na sua maior parte, de uma pesquisa por documentos antigos que representam o que se pensava seriamente vir a ser o mundo que 
nos é hoje familiar. Os objectos de culto deste movimento são aqueles artigos de jornal, filmes ou anúncios publicitários que tentaram seriamente descrever acontecimentos futuros, prevendo máquinas, edificios e pequenas invenções, na sua maior parte ainda hoje para nós totalmente inconcebíveis, passíveis de erradicar qualquer problema e de concretizar os sonhos da humanidade, prevendo automóveis voadores e refeições condensadas numa pílula em cidades onde cada um aceita o seu próprio papel e estatuto sem reservas. O retrofuturismo é a fruição da falência dessas previsões, maioritariamente utópicas, e propõe-se, por isso, como postura irónica e voyeurista em relação aos seus objectos de eleição. A razão de ser deste movimento parece assim elaborar-se sobre a noção de descrédito e como tal adere a uma distanciação, situando-se entre curiosidade e entretenimento, que coincide com uma determinação contemplativa (ou mesmo fetichista) do objecto em questão, negando portanto o carácter activista e continuativo de todo o programa futurista. Quanto muito, a colheita retrofuturista pode ajudar-nos a compreender o presente a partir daquilo no qual ele não se transformou, mas uma abordagem retrofuturista do Futurismo hipoteca uma sua real avaliação, porque é desfeito o nexo de continuidade com o qual, como tentámos mostrar, o Futurismo se constrói.

Uma segunda direcção é precisamente aquela que se dedica a encontrar as linhas continuativas, as sequências formais, os jogos de diferença impulsionados pelo Futurismo ${ }^{11}$. Para descobrir onde persiste um legado futurista devemos munirmo-

11 Esta linha identifica-se com uma leitura histórica cunhada por Mario Perniola com o termo neo-antigo. A sua formulação relaciona o momento egípcio da arte, individuado por Hegel como o mais misterioso e enigmático pela incapacidade de sintetizar os opostos, acabando por conduzir a um indistinto encontro entre o exterior e o interior, entre o sagrado e o profano e entre o orgânico e o inorgânico. Mario Perniola, Il Pensiero Neo-Antico, Mimesis, Roma, 1995. 
-nos dos próprios princípios animadores do movimento, e aqui reside, a nosso ver, o maior alcance e o aspecto principal de todo o movimento. A rentabilização de uma categoria estética funcional e construtiva, como o é o lifestyle, ajuda-nos a procurar a sua pertinência estética actual no âmbito de um alargamento do campo de acção desta disciplina a um conjunto variado de fenómenos sociais, políticos e mediáticos, que simultaneamente espelham e formam o sentir contemporâneo. A continuidade, com a qual o Futurismo concebeu a sua poética, fornece-nos o método, a chave de leitura com a qual nos aventuramos a descobrir onde é que ele continua, onde é que persistem os seus elementos retóricos e compositivos sob outra forma, detectando os aspectos que o caracterizam também como um movimento antecipador. A procura será tanto menos errática quanto mais nos apercebermos dos grandes catalisadores do nosso tempo e de que modo eles actuam na metamorfose dos conceitos suscitados no passado.

Dirigindo a nossa atenção aos efeitos que mais vezes são postos em evidência quando se fala da ordem mundial actual em termos de uma globalização, de massificação e de ampliação mediática, é possível traçar as características que lhes são normalmente associadas, mesmo sem tomar uma posição na contenda política e portanto permanecendo no campo da pura aisthesis. Verificamos, com uma quase inverosímil correlação, que estas coincidem com os princípios da estética futurista e que, actuando como um filtro moderno, cada uma lança o seu novo campo semântico instalando as respectivas problemáticas:

Em primeiro lugar a velocidade e a dinâmica, com as quais se invocam hoje tanto o ritmo frenético dos homens e mulheres de negócios como a rapidez do acesso a informação, a proximidade entre lugares, a falta de tempo ou o impulso em direcção à acção. A "eterna velocidade omnipresente" prescrita no primeiro manifesto como princípio 
ordenador de uma nova estética e de um novo mundo aparece hoje travestida, ampliada e massificada no fenómeno psico-social do stress.

Depois, a violência: “A arte não pode ser outra coisa senão violência, crueldade e injustiça". Neste elemento futurista vemos confluir tanto o aspecto estético da sua postura pública como a exaltação do acidental na arte (exprimindo o encontro entre todos os planos da obra numa interpenetração extrema que tende para a indescernibilidade). $O$ aspecto sensível da ampliação massmediática da violência que remonta à rixa e ao desacato futurista aparece hoje sob a forma da violência urbana, cujas causas parecem residir numa desorientação causada pela contracção do estatuto e do valor intrínseco de todas as coisas até à indiferença generalizante, pela qual qualquer acto equivale a outro e tudo o que vale a pena joga-se aqui e agora. No que diz respeito à relação da violência com a propriedade, pública ou privada, essa degenera no vandalismo. Finalmente, do ponto de vista militar, a violência expandiu-se ao ponto de qualquer intervenção militar ser hoje pensada em termos de uma guerra total, a qual não se refere já apenas a um conflito armado oficial onde todos participam e na qual se assiste a uma gradual anulação das fronteiras entre a esfera militar e a esfera civil, mas sim a uma proliferação dos campos sobre os quais recai a dinâmica da guerra: guerra financeira, guerra psicológica, guerra informática, guerra mediática, etc. ${ }^{12}$.

Quanto à simultaneidade, essa parece-nos surgir com a sua maior expressividade na compreensão contemporânea da dimensão natural e ambiental. Com efeito, uma das mais constantes ideias divulgadas pela ciência é a de que um acto

12 Cf. Angela Pascucci, "La nuova Strategia della guerra totale”, recensão a Qiao Liang e Wang Xiangsui, Guerra senza limiti. L'arte della guerra asimmetrica fra terrorismo e globalizzazione, a cura di Fabio Mini, Libreria Editrice Goriziana 2001, in Le Monde Diplomatique, edição italiana. Disponível em www.mondediplomatique.it/LeMonde-archivio/Novembre-2002/. 
ambientalmente irresponsável não se restringe a afectar apenas o nosso espaço envolvente, mas tem repercussões imediatas na região, no território e no ecossistema, até afectar a Terra inteira que é considerada como um só corpo onde cada parte é sensível. A Terra tornou-se assim uma espécie de unidade conceptual que recolhe instantaneamente as consequências do comportamento de cada um. A simultaneidade futurista, que surge como princípio poético para indicar uma vontade totalizante e triunfante da arte, retorna sob as vestes da emergência ambiental, das alterações climáticas e do aquecimento global.

Seria desviante tomar este conjunto de degenerações: stress, violência urbana, vandalismo, guerra total e emergência ambiental como indicadores que conduziriam a um quase irreparável pessimismo. Mas, mesmo se fossemos tentados a fazer acompanhar a noção de degeneração da noção de degrado, seria o próprio Futurismo a dizer-nos como uma vontade de mudar radicalmente se compromete, antes de mais, com a regeneração. A energia futurista diz-nos que a instalação de um sentimento de aversão em relação a um passado persistente, e a consequente irrupção de uma vontade de mudança, mete em movimento uma sua parte insuspeita, reactivando-se e surgindo sob novas formas com uma carga potencial originadora. 